Article

\title{
Imprinted Polymeric Beads-Based Screen-Printed Potentiometric Platforms Modified with Multi-Walled Carbon Nanotubes (MWCNTs) for Selective Recognition of Fluoxetine
}

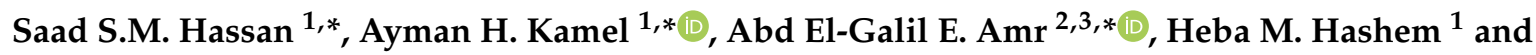 \\ E.M. Abdel Bary ${ }^{4}$ \\ 1 Chemistry Department, Faculty of Science, Ain Shams University, Abbasia, Cairo 11566, Egypt; \\ hebahashem426@yahoo.com \\ 2 Pharmaceutical Chemistry Department, Drug Exploration \& Development Chair (DEDC), College of \\ Pharmacy, King Saud University, Riyadh 11451, Saudi Arabia \\ 3 Applied Organic Chemistry Department, National Research Center, Dokki, Giza 12622, Egypt \\ 4 Chemistry Department, Faculty of Science, Mansoura University, Mansoura 35516, Egypt; \\ ebary301@yahoo.com \\ * Correspondence: saadsmhassan@sci.asu.edu.eg (S.S.M.H.); ahkamel76@sci.asu.edu.eg (A.H.K.); \\ aamr@ksu.edu.sa (A.E.-G.E.A.); Tel.: +20-122-216-2766 (S.S.M.H.); +201-000-361-328 (A.H.K.); \\ +966-565-148-750 (A.E.-G.E.A.)
}

Received: 26 February 2020; Accepted: 17 March 2020; Published: 21 March 2020

\begin{abstract}
Herein, we present a new validated potentiometric method for fluoxetine (FLX) drug monitoring. The method is based on the integration of molecular imprinting polymer (MIP) beads as sensory elements with modified screen-printed solid contact ion-selective electrodes (ISEs). A multi-walled carbon nanotube (MWCNT) was used as a nanomaterial for the ion-to-electron transduction process. The prepared MIP beads depend on the use of acrylamide (AAm) and ethylene glycol dimethacrylic acid (EGDMA) as a functional monomer and cross-linker, respectively. The sensor revealed a stable response with a Nernstian slope of $58.9 \pm 0.2 \mathrm{mV} /$ decade and a detection limit of $2.1 \times 10^{-6} \mathrm{~mol} / \mathrm{L}$ in $10 \mathrm{mmol} / \mathrm{L}$ acetate buffer of $\mathrm{pH} 4.5$. The presented miniaturized sensors revealed good selectivity towards FLX over many organic and inorganic cations, as well as some additives encountered in the pharmaceutical preparations. Repeatability, reproducibility and stability have been studied to evaluate the analytical features of the presented sensors. These sensors were successfully applied for FLX assessment in different pharmaceutical formulations collected from the Egyptian local market. The obtained results agreed well with the acceptable recovery percentage and were better than those obtained by other previously reported routine methods.
\end{abstract}

Keywords: Solid-contact ISEs; multi-walled carbon nanotubes (MWCNTs); fluoxetine; screen-printed electrodes; method validation

\section{Introduction}

Fluoxetine (FLX) is one of the five drugs inserted under the selective serotonin re-uptake inhibitors (SSRIs) category that is used throughout the world as an anti-depressant drug. Depression diagnosis can be expressed as a mental health illness and disability. According to the world federation for mental health, depression is occurring as a reason for different problems that affect the behavior of humans. It can cause economic problems, increase the rate of unemployment and it is a main reason for family disturbance [1]. It can also cause occupational stress when the worker is facing work demands and is not matched with its requirements [2]. Fluoxetine hydrochloride was approved by the US Food and 
Drug Administration (FDA) organization since 1987 for depression treatment [3]. It is administered by the oral route and possesses a unique effect on the obsessive-compulsive disorder [4,5].

There are different methods of FLX determination in pharmaceutical forms and biological fluids reported in the literature. Among these methods are spectrophotometry [5-8], capillary electrophoresis [9-11], high-performance liquid chromatography (HPLC) [12,13], gas chromatography-mass spectrometry technique [14,15], fluorimetry [16], voltammetry [17-20] and potentiometry [21-23].

Unlike the conventional liquid-contact ISEs, solid-contact ISEs which eliminate the internal solution, are easily miniaturized and have been recognized as the next generation of ISEs. It is well known that the electrode substrates for these electrodes are usually made from expensive materials such as glassy carbon, gold or platinum. This reveals serious limits to their wide use, especially in less developed countries. For cost-effectiveness, fast, accessible and precise analysis, simple instrumentation, and incorporated functionality, screen-printed ISEs have been chosen for flexible, reliable and low-cost platforms for potentiometric analytical devices [24-26]. In addition, this type of electrode offers a practical viable method without sample pretreatment, prolonged analysis time and sophisticated experimental establishment.

Molecularly imprinted polymers (MIPs) possess pre-defined specific recognition cavities designed for the target analyte. They are stable to extremes of $\mathrm{pH}$, organic solvents and temperature, which provides for more flexibility in the development of analytical and bioanalytical methods [27-29]. MIPs have a valuable impact on the enhancement of ion-selective electrodes, in which the encapsulated molecules, attached via their high affinity three-dimensional cavities, act as tailor-made highly specific receptor sites for the desired molecule [30-36]. In addition, the developed membrane potential in ISEs does not require the extraction of the template from the molecular imprinting skeleton. There are also no size restrictions on the template compound because species do not have to diffuse through the membrane.

Herein, a new, simple and cost-effective method for FLX determination using a ceramic screen-printed planar electrode is presented. Artificial receptors for FLX based on template imprinted polymers were synthesized using thermal precipitation polymerization and acrylamide (AAm) as an appropriate monomer. The properties of the proposed sensor can be studied via different features, which reflect the high sensitivity, selectivity with low potential drifts, stability and more applicability of investigated sensors in pharmaceutical preparations.

\section{Materials and Methods}

\subsection{Reagents and Chemicals}

For MIPs synthesis and membrane fabrication, all chemicals were obtained from Sigma Aldrich (St. Louis, Missouri, MO, USA) such as high molecular weight poly (vinyl chloride) (PVC), dioctyl phthalate (DOP), 2-nitrophenyl octyl ether (o-NPOE), bis (2-Ethylhexyl) sebacate (DOS), sodium tetraphenylborate (TPB), acrylamide (AAm), benzoyl peroxide (BPO) and ethylene glycol dimethacrylate acid (EGDMA 98\%). Tetrahydrofuran (THF) and acetonitrile were obtained from Fluka AG (Buchs, Switzerland). Tetrahydrofuran (THF) was freshly distilled prior to use. In addition, MWCNTs were purchased from (EPRI, Cairo, Egypt). Fluoxetine.HCl pure drug was obtained from Pharaonia Pharmaceuticals (Alexandria, Egypt). Fluoxetine capsules were obtained from pharmacies in Egypt, which were represented with different commercial names such as Prozac (Lilly, France), Philozac (Amoun, Egypt), Flutin (Eipico, Egypt) and Depreban (Amirya, Egypt). All these commercial names contained $20 \mathrm{mg}$ FLX per capsule.

A definite weight of pure $\mathrm{FLX} \cdot \mathrm{HCl}$ drug was dissolved in $100 \mathrm{~mL}$ double distilled water to prepare a stock solution of $1.0 \times 10^{-2} \mathrm{~mol} / \mathrm{L}$. Also, $10 \mathrm{mmol} / \mathrm{L}$ acetate buffer solution of $\mathrm{pH} 4.5$ was prepared for calibration measurements. The working solutions $\left(1.0 \times 10^{-2}-1.0 \times 10^{-7} \mathrm{~mol} / \mathrm{L}\right)$ were prepared with accurate dilutions and stored in brown bottles in the refrigerator. 


\subsection{Apparatus}

An attenuated total reflection (ATR) Fourier transform spectrometer (Thermo-Fisher Scientific iS10, Austin, TX, USA) and a scanning electron microscope (SEM) (JEOL JSM 6510lV, Osaka, Japan) were used for characterization of MIP particles. The binding analysis was investigated by using a Shimadzu UV/VIS spectrophotometer (Shimadzu UV-1601 PC, Osaka, Japan) for absorbance measurements. A bench $\mathrm{pH} / \mathrm{mV}$ meter (Jenway ${ }^{\mathrm{TM}}$ 3510) was used for all potential measurements as a combination of drop-casted FLX membrane on the screen-printed and Jenway ${ }^{\mathrm{TM}} \mathrm{Ag} / \mathrm{AgCl}$ double junction reference electrode filled in the outer compartment with $1 \mathrm{M} \mathrm{CH}_{3} \mathrm{COOLi}$. For necessary $\mathrm{pH}$ measurements, a Jenway ${ }^{\mathrm{TM}} 3505$ combined glass $\mathrm{pH}$ electrode was used. Also, the reference method was applied by using high-performance liquid chromatography (HPLC) coupled with a UV/VIS detector (Series 200 Pump, Perkin Elmer, Waltham, MA, USA).

\subsection{Synthesis of MIPs}

Host-tailored three-dimensional polymeric particles (MIPs) were synthesized with precipitation polymerization. An amount of $3.0 \mathrm{mmol}$ of cross-linked AAm monomer with $3.0 \mathrm{mmol}$ of EGDMA was mixed with $1.0 \mathrm{mmol}$ of FLX as a template. The polymerization process was initiated by adding $80 \mathrm{mg}$ of BPO into a cocktail that was dissolved in $15 \mathrm{~mL}$ of acetonitrile in $(20 \mathrm{~mL})$ a sealed tube. To complete the polymerization, the $\mathrm{N}_{2}$ stream was diffused into the cocktail solution for $5 \mathrm{~min}$, followed by good sealing of the tube. Also, the tube was maintained in paraffin wax at $70^{\circ} \mathrm{C}$ for $20 \mathrm{~h}$. All previous steps were repeated for non-imprinted polymer (NIP) synthesis without the addition of the FLX template. The resulting powders were washed after drying with absolute ethanol several times in soxhlet for $48 \mathrm{~h}$. MIP and NIP were left until complete dryness at room temperature before using them. A scheme of the stepwise fabrication process of the biomimetic receptor is presented in Figure 1.

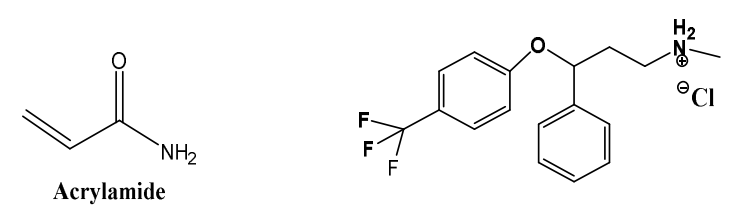

Fluoxetine hydrochloride<smiles>C=C(C)C(=O)OCCOC(=O)C(=C)C</smiles>

Ethylene glycol dimethacrylate

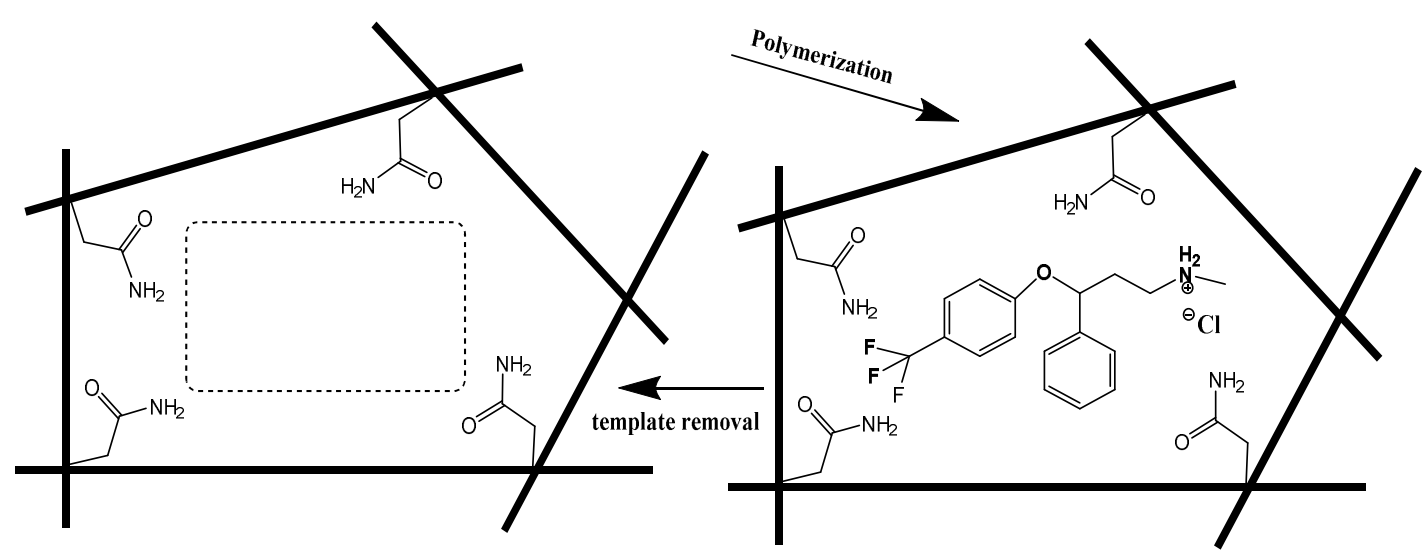

Figure 1. Schematic representation of noncovalent imprinting.

\subsection{Fabrication of the Sensors and EMF Measurements}

The screen-printed electrode (SPE) is fabricated as a planar chip of $0.1 \mathrm{~mm}$ thickness and $35 \mathrm{~mm}$ length containing two sensing orifices of $2 \mathrm{~mm}$ width. These orifices were made from carbon ink and printed on an alumina substrate to be the area of the membranes' drop-castings. Different membranes were prepared with $68.0 \mathrm{mg}$ of PVC powder, $2.0 \mathrm{mg}$ of additive (TPB) and $12.0 \mathrm{mg}$ of MIP. The previous 
membranes contained $118.0 \mathrm{mg}$ of different plasticizers such as DOP, $\mathrm{o}-\mathrm{NPOE}$ or DOS and $3.0 \mathrm{~mL}$ of THF was used to dissolute all previous components. The screen-printed chip was modified with drop-casting of $10 \mu \mathrm{L}$ of MWCNTs $(0.1 \mathrm{~g} / 25 \mathrm{~mL}$ THF) on sensing orifices onto which $10 \mu \mathrm{L}$ of ionophore containing membranes was drop-casted and was left to dry for $5 \mathrm{~min}$.

Then, these sensors were soaked in $1.0 \times 10^{-2} \mathrm{~mol} / \mathrm{L}$ FLX solution for $2 \mathrm{~h}$ before using. The same solution was also used for sensors storage. All potential measurements were applied after potential stabilization $\pm 2 \mathrm{mV}$ and the results were plotted, to display the resulting EMF values versus logarithm [FLX] concentration obtained.

\subsection{Analytical Applications}

FLX was administered via the oral route, which was represented commercially as Prozac, Philozac, Flutin and Depreban capsules containing $20 \mathrm{mg} /$ capsule. A stock of FLX was prepared by mixing 20 capsules' contents (20 mg per one capsule), weighing and calculating the mean weight of the active ingredient in one capsule. An accurately weighed amount of the powder equivalent to $3.4 \mathrm{~g}$ of FLX was dissolved in $100 \mathrm{~mL}$ dist- $\mathrm{H}_{2} \mathrm{O}$ to obtain $10^{-1} \mathrm{~mol} / \mathrm{L}$ FLX stock. The previous contents were sonicated until complete dissolution for $45 \mathrm{~min}$ and the resultant solution was filtered. Different concentrations were prepared from dilution of the supernatant to obtain $10^{-2}$ to $10^{-4} \mathrm{~mol} / \mathrm{L}$. The calibration curve was established between the potential readings versus $\log [\mathrm{FLX}]$ and compared with the similar curve of the pure drug under the same conditions.

\section{Results and Discussion}

\subsection{Characterization of the MIP Particles}

Figure 2 shows the FT-IR spectra of the FLX drug, unwashed and washed MIP, in addition to the NIP beads. First, strong peaks of FLX that appeared at 2951 and $2924 \mathrm{~cm}^{-1}$ are attributed to the asymmetric $\mathrm{C}-\mathrm{H}$ stretches and the three strong peaks at 2805, 2733 and $2450 \mathrm{~cm}^{-1}$ refer to $\mathrm{NH}_{2}{ }^{+}$ stretches. All peaks that appeared at 1614, 1598 and $1534 \mathrm{~cm}^{-1}$ exhibited from phenyl ring vibrations and $C=C$ stretching. $C-F$ stretching is assigned at $1326 \mathrm{~cm}^{-1}$. Strong and sharp peaks at 1161 and $1118 \mathrm{~cm}^{-1}$ attributed to $\mathrm{C}-\mathrm{N}$ stretches of a secondary amine and $-\mathrm{C}-\mathrm{O}$ in aryl ether. In the unwashed MIP spectrum, it can be shown that the clear peaks at 3362 and $1167 \mathrm{~cm}^{-1}$ refer to $\mathrm{N}-\mathrm{H}$ stretching and $\mathrm{C}-\mathrm{N}$ of the secondary amine group that present in FLX, respectively. Medium peaks at 1614 and $1324 \mathrm{~cm}^{-1}$ attributed to phenyl ring vibrations and C-F stretches, which appeared in FLX spectra, confirm the progress of the imprinting process between FLX and cross-linked AAm monomer. The strong and sharp peak of cross-linked AAm monomer in MIPs and NIPs that appeared at $1717 \mathrm{~cm}^{-1}$ corresponds to $-\mathrm{C}=\mathrm{O}$ and all peaks from 1256 to $1128 \mathrm{~cm}^{-1}$ corresponds to $-\mathrm{C}-\mathrm{O}$ stretching of the polymeric backbone. In washed MIP and NIP, it is clear that there is a complete disappearance of assignable peaks at 1614 and $1324 \mathrm{~cm}^{-1}$ that refer to phenyl ring vibrations and C-F stretches in FLX, respectively. In addition, the appearance of new strong and broad peaks at $3433-3427 \mathrm{~cm}^{-1}$ and medium peaks at $1658-1650 \mathrm{~cm}^{-1}$ are due to $\mathrm{N}-\mathrm{H}$ stretching and $\mathrm{N}-\mathrm{H}$ bending in AAm, respectively. This confirms the complete removal of FLX molecules from MIP and good preparation of MIP, which can be used in the sensing part of an applied sensor.

As shown in Figure 3, the morphologies of MIP and NIP surfaces were examined by using a scanning electron microscope (SEM). Figure 3A shows the high uniformity of spherical beads of non-imprinted polymer (NIP) with mean diameter of about $1.8 \mu \mathrm{m}$. On the other hand, the morphology of washed MIP is showed in Figure 3B as irregular nano-beads with a mean diameter around $0.7 \mu \mathrm{m}$. Various morphologies of MIP and NIP confirm the investigation of the imprinting process that ensures efficient MIP as an adequate ionophore in the proposed sensor. 


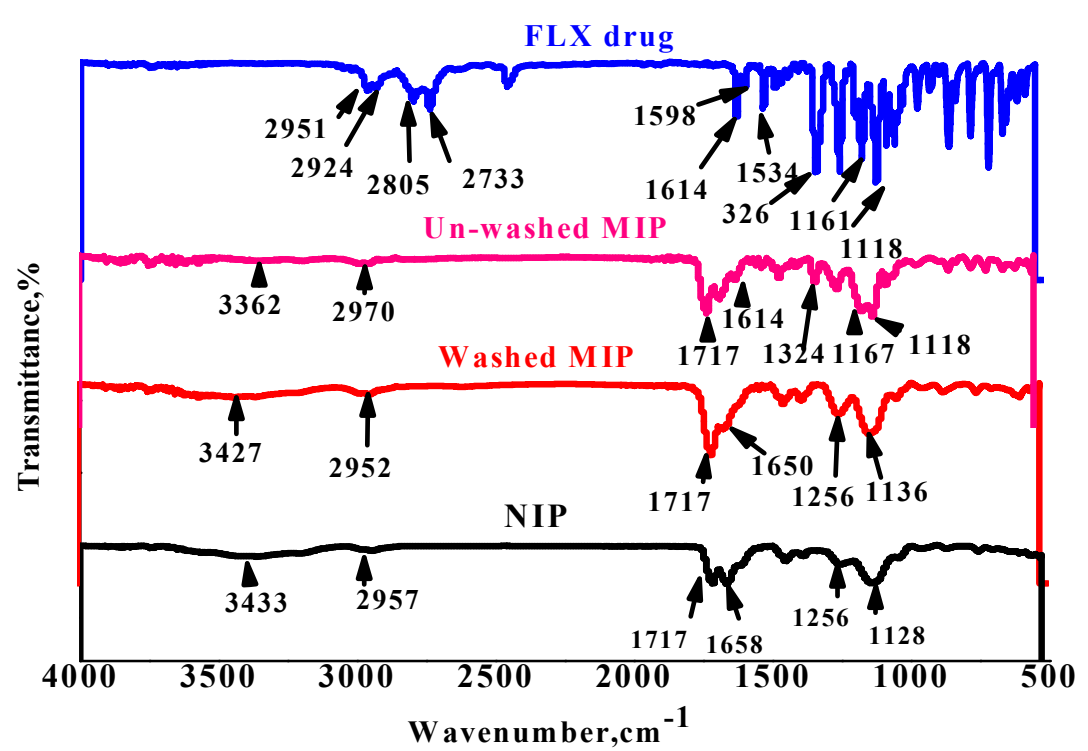

Figure 2. FT-IR spectra of fluvoxamine (FLX), FLV/MIP, washed molecular imprinting polymer (MIP) and non-imprinted polymer (NIP) beads.

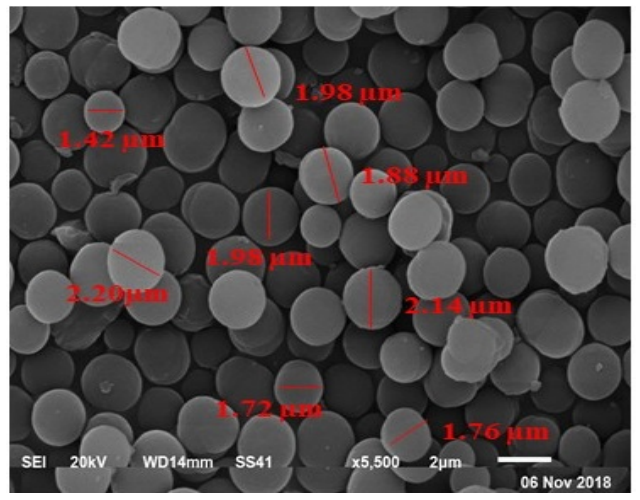

(A)

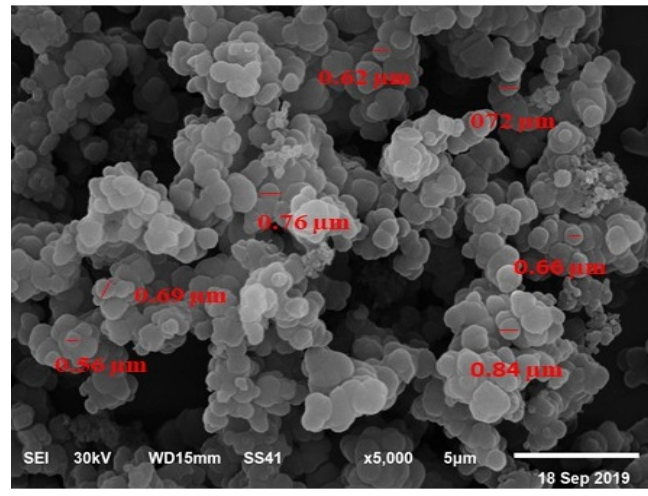

(B)

Figure 3. Scanning electron microscope (SEM) images of (A) NIP beads and (B) washed MIP beads.

The affinities and adsorption capacities of MIP and NIP can be studied by the binding experiment that shows two isotherms in Figure 4A. There are clear differences between MIP and NIP in adsorption capacities for the drug, which reveal that MIP has higher affinity sites than NIP. These sites refer to cavities of the leaved drug molecules after washing beside the functional groups on the surface. The adsorption capacities of polymers increased with increase in FLX concentration. The free FLX concentrations were determined by spectrophotometric technique at $\lambda_{\max }=226 \mathrm{~nm}$. The binding capacity of MIP and NIP were calculated according to the following equation:

$$
Q=\mu m o l\left(F L X_{\text {bound }}\right) /[m(N I P / M I P)]=\left(C_{i}-C_{f}\right) V s \times 1000 /[m(N I P / M I P)]
$$

where $Q$ is the binding capacity of NIP or MIP ( $\mu \mathrm{mol} / \mathrm{g}), C_{i}, C_{f}, V_{s}$ and $\mathrm{m}(\mathrm{NIP} / \mathrm{MIP})$ are the initial FLX concentration $(\mu \mathrm{mol} / \mathrm{mL})$, the final FLX concentration $(\mu \mathrm{mol} / \mathrm{mL})$, the volume of the tested solution $(\mathrm{mL})$ and the mass of dried polymer $(\mathrm{g})$, respectively. 


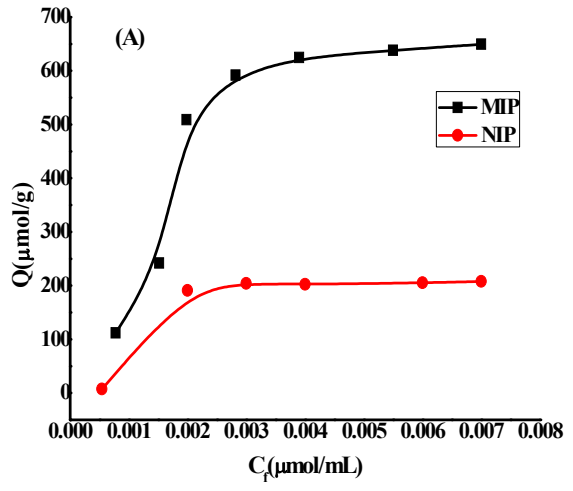

(A)

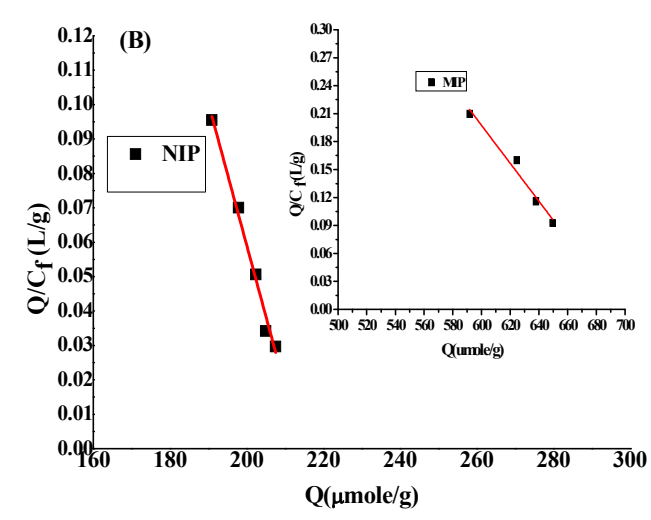

(B)

Figure 4. (A) Binding isotherm and (B) Scatchard plot for MIP and NIP.

Furthermore, a Scatchard analysis model as shown in Figure 4B was evaluated to give binding capacity and dissociation constant values at binding sites of NIP and MIP according to following equation:

$$
Q / C_{f}=\left(Q_{\max }-Q\right) / K_{d}
$$

where $Q$ is the binding capacity, $C_{f}, Q_{\max }$ and $K_{d}$ are the free analytical concentration at equilibrium $(\mu \mathrm{mol} / \mathrm{mL})$, the maximum apparent binding capacity and the dissociation constant at binding sites, respectively.

The results of $K_{d}$ and $Q_{\max }$ values are $500.00 \mu \mathrm{mol} / \mathrm{L}$ and $709.50 \mu \mathrm{mol} / \mathrm{g}$, respectively for MIP and $250.0 \mu \mathrm{mol} / \mathrm{L}$ and $221.3 \mu \mathrm{mol} / \mathrm{g}$, respectively for NIP. These values reflect the higher affinities of binding sites of MIP than NIP, which is attributed to formation of specific and selective cavities of MIP through the polymerization steps and after washing the polymer beside the presence of functional binding groups in MIP and NIP. Also, one regression line of two polymers is shown in the Scatchard analysis model that refers to the uniformity and homogeneity of the binding sites of NIP and MIP.

The presence of the template during the polymerization can be measured with the imprinting factor (IF) as follows:

$$
I F=\left[Q_{\max }(M I P)\right] /\left[Q_{\max }(N I P)\right]
$$

where $Q_{\max }(\mathrm{MIP})$ and $Q_{\max }(\mathrm{NIP})$ are maximum binding capacities of the imprinted and the non-imprinted polymers, respectively. The imprinting factor (IF) is calculated to be 3.2.

\subsection{Sensor Analytical Features}

FLX is represented as one of the physiologically active amines category that is introduced from pharmaceutical products, which contains an amine functional group [37]. The sensitivity and selectivity of analytes in ISEs can be controlled by introducing the carrier capable of selectively binding of the drug in the membrane by changing the nature of the ion exchanger (additive) or by changing the nature of the plasticizer. The presence of the plasticizer that contains polar or polarizable groups acts as a solvent-mediator of PVC and ionophore, and prevents its exudation from the polymeric matrix to the solution. Therefore, the three different membranes can be prepared to contain MIP as ionophore or carrier with $\mathrm{TPB}^{-}$as an additive and PVC plasticized in DOP, $o-\mathrm{NPOE}$ or DOS, separately.

For studying the electrochemical behavior and analytical features of an FLX-MIP sensor, three previous membranes were prepared as cocktails in THF and were spotted individually by $10 \mu \mathrm{L}$ on the on-sensing orifices of the screen-printed electrode, which was modified with $10 \mu \mathrm{L}$ of MWCNT as a solid contact substance.

The influences of the polarity and chemical nature of each plasticizer on the potentiometric response of the proposed sensor were investigated. In order for the plasticizer to be adequate for using 
in the polymeric liquid membranes in ISEs it must have high molecular weight high lipophilicity, low vapor pressure and high capacity of dissolving the substrate and other components that are found in the polymeric membrane. Additionally, the most important parameters that may affect its behavior are dielectric constant $\left(\varepsilon_{\mathrm{o}}\right)$ and its viscosity [37]. By comparing the results as can be seen in Table 1, the best cationic slopes response, which is near-Nernestian, is for the electrodes of MIP-FLX membranes; their responses are $57.1 \pm 0.3$ and $58.9 \pm 0.2 \mathrm{mV} /$ decade with detection limits $4.9 \times 10^{-6}$ and $2.1 \times 10^{-6}$ $\mathrm{mol} / \mathrm{L}$, plasticized with DOP $(\varepsilon \mathrm{O}=5.1)$ and $o$-NPOE $(\varepsilon \mathrm{O}=24)$, respectively. But the best detection limit can be investigated with the membrane plasticized with DOS $(\varepsilon 0=4.6)$ is $1.4 \times 10^{-6} \mathrm{~mol} / \mathrm{L}$ with near-Nernestian slope $(56.0 \pm 0.6 \mathrm{mV} /$ decade $)$ (Figure 5).

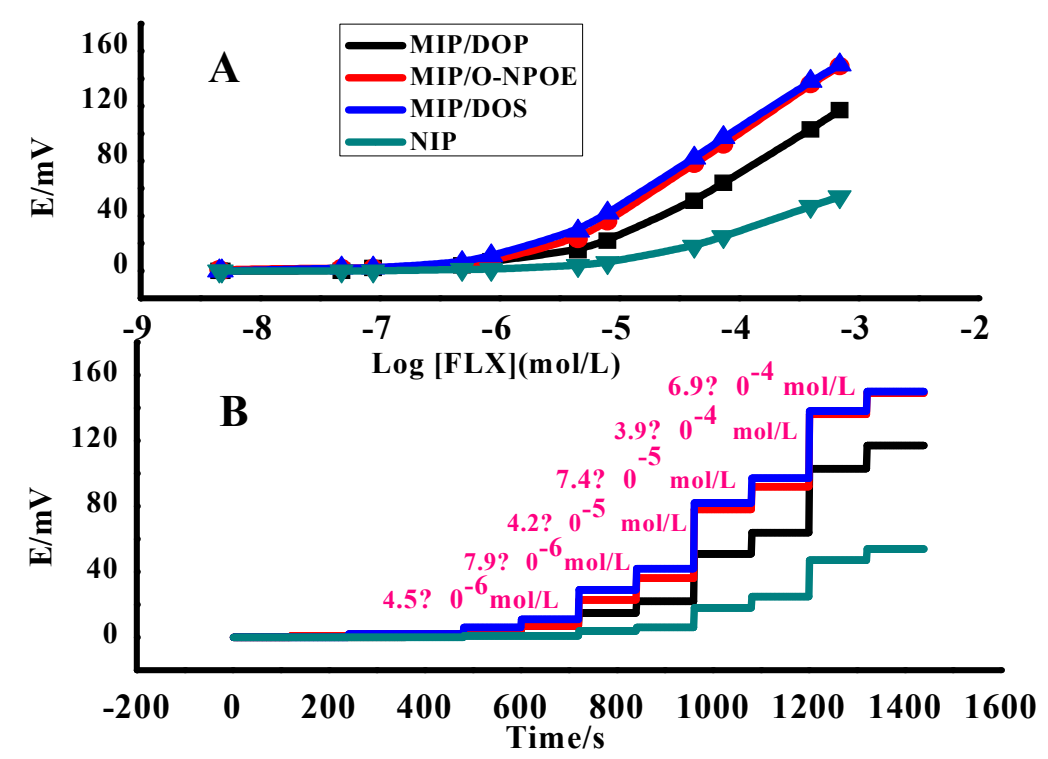

Figure 5. (A) Calibration plots and (B) time response of non-imprinted polymer (NIP) and the proposed sensors in acetate buffer $(0.01 \mathrm{M}) \mathrm{pH}=4.5$ with multi-walled carbon nanotube (MWCNT) as a transducer.

Although the dielectric constant $(\varepsilon \mathrm{o})$ of $o$-NPOE is the highest value, its nature can't affect results purely based on the electrode performance comparing with the nature of the drug that has primary amine active sides and adding the tetraphenyl borate (TPB) as ion-exchanger or additive in the membrane. Therefore, the results confirm that the dielectric constant of the plasticizers, used as solvent-mediators, does not effect in a significant manner the potentiometric detection limit of the membrane in the case of an FLX drug [38].

Remarkably, the effect of the presence of MIP, NIP and TPB individually in the membranes also can be investigated. Table 1 shows that the sub-Nernestian slope of the sensor of NIP $(29.8 \pm 1.3 \mathrm{mV} / \mathrm{decade})$ and its detection limit $\left(1.2 \times 10^{-5} \mathrm{~mol} / \mathrm{L}\right)$ confirm the influence of the imprinting factor of MIP that has higher affinity and sensitivity for FLX molecules with near-Nernestian slope ( $48.8 \pm 0.5 \mathrm{mV} /$ decade $)$ and lower detection limit $\left(8.5 \times 10^{-6} \mathrm{~mol} / \mathrm{L}\right)$. In the case of the presence of TPB without MIP in the membrane shows the near-Nernestian slope $(50.9 \pm 0.3 \mathrm{mV} /$ decade $)$ and low detection limit $\left(7.1 \times 10^{-6} \mathrm{~mol} / \mathrm{L}\right)$ due to its ion-exchange nature. However, it is clear that the presence of both MIP and TPB in the membrane enhances the potentiometric features of the proposed sensor and increases its sensitivity with near-Nernestian slope $(57.1 \pm 0.3 \mathrm{mV} /$ decade $)$ for detection limit $\left(4.9 \times 10^{-6} \mathrm{~mol} / \mathrm{L}\right)$. Figure 6 represents a proposed mechanism for the potential development across the membrane. 
Table 1. The potentiometric response of the fluoxetine (FLX) membranes sensor.

\begin{tabular}{|c|c|c|c|c|c|c|c|c|c|c|}
\hline \multirow{2}{*}{ No } & \multirow{2}{*}{ MIP, mg } & \multirow{2}{*}{ NIP, mg } & \multirow{2}{*}{ TPB, mg } & \multicolumn{3}{|c|}{ Plasticizer, mg } & \multirow{2}{*}{ PVC, mg } & \multirow{2}{*}{ * Slope, (mV/Decade) } & \multirow{2}{*}{ Detection Limit, (mol/L) } & \multirow{2}{*}{$\mathbf{r}^{2}$} \\
\hline & & & & DOP & o-NPOE & DOS & & & & \\
\hline 1 & 12.00 & - & 2.00 & 118.00 & - & - & 68.00 & $57.1 \pm 0.3$ & $4.9 \times 10^{-6}$ & 0.999 \\
\hline 2 & 12.00 & - & 2.00 & - & 118.00 & - & 68.00 & $58.9 \pm 0.2$ & $2.1 \times 10^{-6}$ & 0.999 \\
\hline 3 & 12.00 & - & 2.00 & - & - & 118.00 & 68.00 & $56.0 \pm 0.6$ & $1.4 \times 10^{-6}$ & 0.999 \\
\hline 4 & 12.00 & - & - & 118.00 & - & - & 68.00 & $48.8 \pm 0.5$ & $8.5 \times 10^{-6}$ & 0.999 \\
\hline 5 & - & 12.00 & - & 118.00 & - & - & 68.00 & $29.8 \pm 1.3$ & $1.2 \times 10^{-5}$ & 0.999 \\
\hline 6 & - & - & 2.00 & 118.00 & - & - & 68.00 & $50.9 \pm 0.3$ & $7.1 \times 10^{-6}$ & 0.999 \\
\hline
\end{tabular}




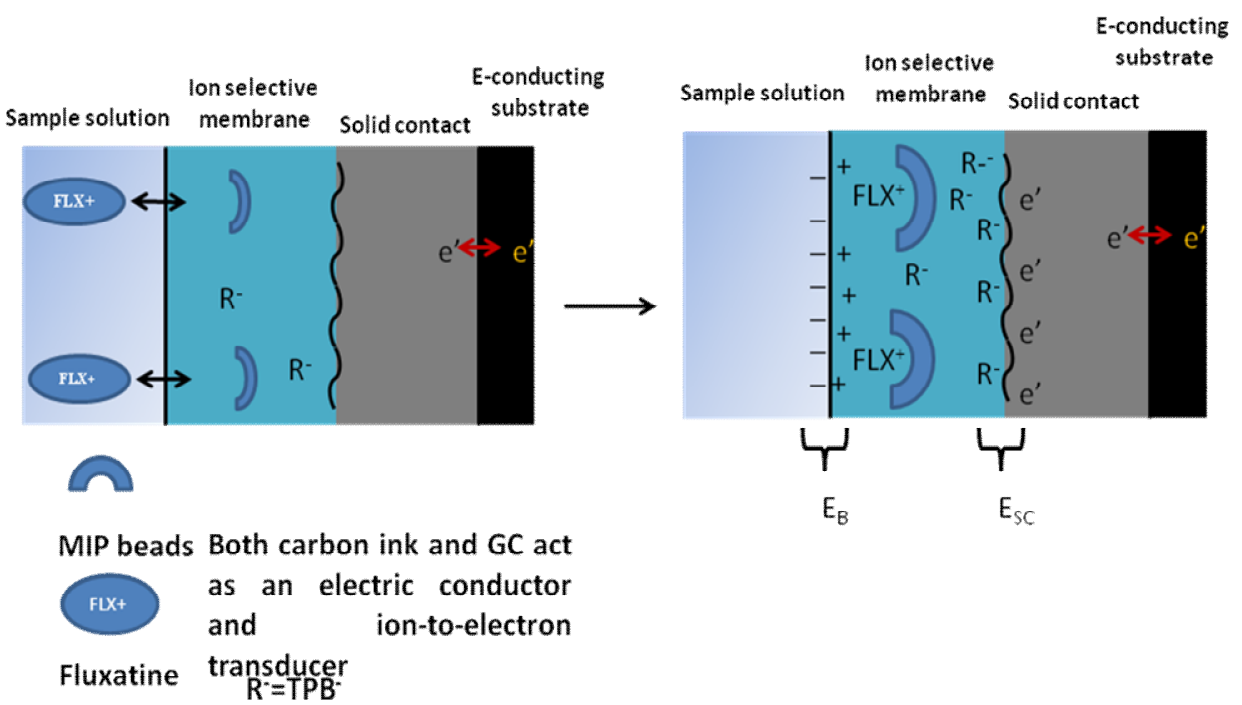

Figure 6. Proposed mechanism for potential development.

As previously shown in Figure 5, the dynamic response of the proposed sensors was examined over the concentration range $1.0 \times 10^{-7}-1.0 \times 10^{-2} \mathrm{~mol} / \mathrm{L}$ of FLX solution. The results exhibited by response values taken every 3 s over 2 min for each half $\mathrm{mL}$ of each concentration show a fast and stable potentiometric response $(<10 \mathrm{~s})$. This refers to the high performance of the proposed sensor in the FLX determination. Note the water layer formation test and the comparison between the presence of the MWCNT layer and its absence are shown in Figure 7. MWCNT lipophilicity was tested by immersing the applied sensor, in its two cases of the presence and absence of MWCNT, in the buffer of $\mathrm{pH} 4.5$ for $30 \mathrm{~min}$; then the solution was alternated to be $9.1 \times 10^{-5} \mathrm{~mol} / \mathrm{L}$ of FLX for $30 \mathrm{~min}$ and finally was replaced with a buffer for $30 \mathrm{~min}$. As shown in Figure 7, the presence of MWCNT offered the potential stability of the applied sensor over the measuring time and decreased the observed potential drift that exhibited from its absence. This remarkable result confirms the lipophilicity of MWCNT and its role in the decrease of water layer formation that could be the reason for the potential drift and the enhancement of the potential stability of the applied sensor.

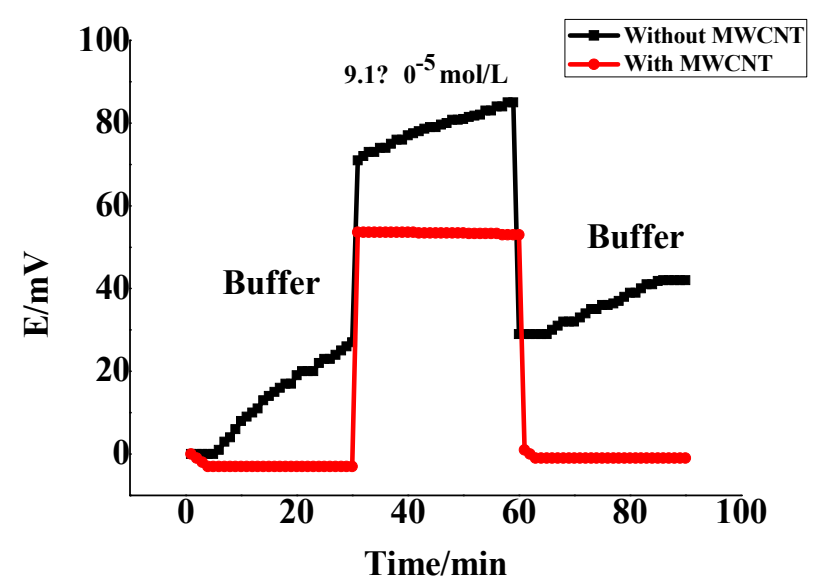

Figure 7. Water-layer tests for the FLX-ISE with and without MWCNT as the solid contact.

\subsection{Method Validation}

The U.S. Food and Drug Administration (FDA) has announced recommendations to support applicants in providing analytical methods, verification data, and samples. These recommendations help to validate the analytical procedures and controls documentation [39]. To ensure the reliability, 
reproducibility and consistency of the analytical data sets of the proposed sensor of FLX-MIP with its new features, three batches ( 5 replicates each) of a standard solution of FLX were used to exhibit the linear range, detection limit, precision (standard deviation) and accuracy (trueness), through response stability, method robustness and selectivity.

\subsubsection{Detection Limit and Method Linearity}

The reliability of the detection limit data was determined by the cross point method according to IUPAC Recommendations [40]. The practical lower limit of detection (LOD) was taken as the concentration of FLX at the point of intersection of the extrapolated linear midrange and final low concentration level segments of the calibration plot as shown in Figure 5a. The exhibited data of LOD are recorded as $4.9 \times 10^{-6}(1.7 \mu \mathrm{g} / \mathrm{mL}), 2.1 \times 10^{-6}(0.7 \mu \mathrm{g} / \mathrm{mL})$ and $1.4 \times 10^{-6} \mathrm{~mol} / \mathrm{L}(0.5 \mu \mathrm{g} / \mathrm{mL})$ of sensors 1, 2 and 3, respectively. The linear range of each calibration graph was $1.0 \times 10^{-2}-6.3 \times 10^{-6}$, $1.0 \times 10^{-2}-5.5 \times 10^{-6}$ and $1.0 \times 10^{-2}-4.7 \times 10^{-6} \mathrm{~mol} / \mathrm{L}$ of sensors 1,2 and 3 , respectively.

\subsubsection{Method for Accuracy and Precision}

Accuracy can also be reported as trueness or percent error (closeness of the agreement between the result of a measurement and a true value) that is calculated from Equation (4). The reproducibility of a set of measurements is concluded as precision or standard deviation (RSD), which can be shown in Equation (5).

$$
\begin{gathered}
\% \text { error }=(\text { Actual value }- \text { expected value }) / \text { expected value } \times 100 \\
\qquad S=\sqrt{ }\left[\sum\left(x i-x^{\prime}\right)^{2} /(n-1)\right]
\end{gathered}
$$

Alternatively, the standard deviation can be expressed as the percent relative standard deviation, RSD \%:

$$
R S D \%=S / X^{\prime} \times 100
$$

where $\mathrm{x}, \mathrm{x}_{\mathrm{i}}$ and $\mathrm{n}$ are the mean result, one of the $\mathrm{n}$ deferent results and number of measurements, respectively.

The precision of this method was examined by using six replicate measurements of $5 \mu \mathrm{g} / \mathrm{mL}$ of FLX solution. The exhibited results of relative standard deviation were $1.7 \%, 1.6 \%$ and $0.6 \%$ of sensors 1,2 and 3 , respectively.

\subsubsection{Method Ruggedness (Robustness)}

The $\mathrm{pH}$ dependence of the proposed sensor was examined over the $\mathrm{pH}$ range of 2-8. The potential readings were recorded for two solutions of FLX $\left(10^{-3}\right.$ and $\left.10^{-4} \mathrm{~mol} / \mathrm{L}\right)$ at various $\mathrm{pHs}$ by using $\mathrm{HCl}$ and/or $\mathrm{NaOH}$ solutions for adjustments. Figure 8 shows the behavior of the proposed sensor in the different $\mathrm{pH}$ values; it shows the wide stability over the $\mathrm{pH}$ range from 2 to 5.2 , which was used as a working range. However, in the range higher than $\mathrm{pH} 5.2$ a significant decrease in $\mathrm{pH}$ was detected. This decrease can be exhibited from the increasing $\mathrm{pH}$ and increasing $\mathrm{OH}^{-}$species in the tested solution that caused the FLX base precipitation. A solution of acetate buffer $(10 \mathrm{mmol} / \mathrm{L})$ at $\mathrm{pH} 4.5$ was chosen to be a working $\mathrm{pH}$ for all potentiometric measurements in this study.

\subsubsection{Sensors' Selectivity}

The potentiometric selectivity of the proposed sensor was investigated by using the modified separate solution method (MSSM) [26]. In addition, the effect of different plasticizers on the selectivity coefficient $\left(\log K^{p o t} F L X, J\right)$ was tested by using different membranes containing DOP, $o$-NPOE or DOS as solvent-mediators in the proposed sensor. There were various interfering cationic species such as inorganic species $\left(\mathrm{Na}^{+}, \mathrm{K}^{+}, \mathrm{Mg}^{2+}, \mathrm{Ca}^{2+}\right.$ and $\mathrm{Ba}^{2+}$ ), amino acids (alanine and arginine), sugars (glucose and lactose), and organic molecules such as caffeine, with the co-administered drug FLX (Sildenafil) were tested. Some of the previous interferences can be found in the dosage forms of FLX or in the 
biological fluids. As shown in Table 2, the results reflect no significant interference of these species with FLX determination. However, the best values of $\log K^{p o t}{ }_{F L X, J}$ are in the case of using DOS as a plasticizer in the proposed sensor.

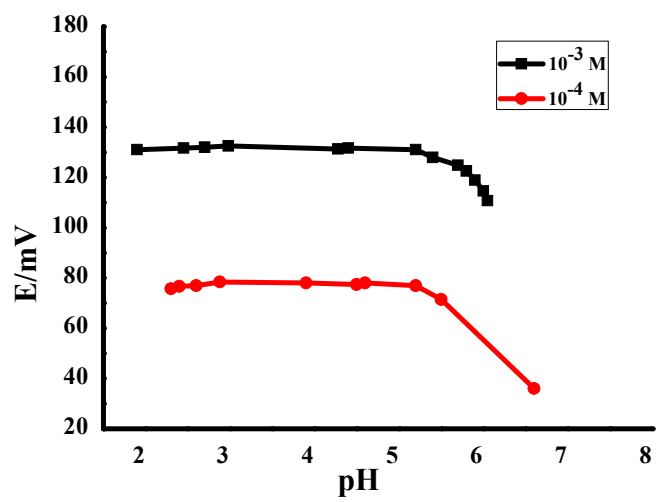

Figure 8. The effect of $\mathrm{pH}$ on the potentiometric response of the applied sensor.

Table 2. The selectivity coefficients ( $\left.\log \mathrm{K}^{\mathrm{pot}} \mathrm{FLX}, \mathrm{J}\right)$ of the proposed sensor.

\begin{tabular}{cccc}
\hline \multirow{2}{*}{ Interfering Ion } & \multicolumn{3}{c}{$-\log ^{\text {Kot }}{ }^{\text {FLX, } \mathbf{~}}$} \\
\cline { 2 - 4 } & DOP & $\boldsymbol{o}$-NPOE & DOS \\
\hline $\mathbf{N a}^{+}$ & 5.0 & 5.0 & 5.7 \\
$\mathbf{K}^{+}$ & 4.7 & 5.0 & 5.3 \\
$\mathbf{M g}^{2+}$ & 5.0 & 4.9 & 5.4 \\
$\mathbf{C a}^{2+}$ & 5.0 & 4.9 & 5.6 \\
$\mathbf{B a}^{2+}$ & 4.7 & 4.9 & 5.6 \\
Alanine & 4.9 & 4.7 & 5.6 \\
Arginine & 7.1 & 6.1 & 7.1 \\
Glucose & 5.0 & 5.0 & 5.7 \\
Lactose & 4.7 & 5.0 & 5.7 \\
Caffeine & 5.0 & 5.0 & 5.7 \\
Sildenafil & 3.2 & 2.8 & 3.5 \\
\hline
\end{tabular}

\subsection{Potential Stability}

The short-term potential stability of the all-solid-state was evaluated by applying the constant-current chronopotentiometry (CP) technique. This technique has been developed by Bobacka's group [39]. All the measurements were applied in a solution of $10^{-3} \mathrm{~mol} / \mathrm{L}$ of FLX in acetate buffer $(10 \mathrm{mmol} / \mathrm{L})$ of $\mathrm{pH} 4.5$ at room temperature $25^{\circ} \mathrm{C} \pm 1{ }^{\circ} \mathrm{C}$ by using a one-compartment three-electrode cell using (NOVA 2.0 software; Metrohm Auto lap B.V. Utrecht, The Netherlands) attached with a Pt auxiliary electrode and a reference electrode $(\mathrm{Ag} / \mathrm{AgCl} / \mathrm{KCl}(3 \mathrm{~mol} / \mathrm{L})$. The applied current is $\pm 1 \mathrm{nA}$ for the $60 \mathrm{~s}$. As shown in Figure 9A, the comparison between the potential stability of the applied sensor in the presence and the absence of MWCNT as a solid contact material and transducer was investigated. The bulk resistance $\left(R_{b}\right)$ that exhibited from the membrane components that equal $0.35 \mathrm{M} \Omega$ was affected by the presence of MWCNT to be $0.19 \mathrm{M} \Omega$. Exhibited capacitance $\left(\mathrm{C}_{\mathrm{L}}\right)$ values incredibly increased from $3.7 \mu \mathrm{F}$ to $160.0 \mu \mathrm{F}$ in the presence of MWCNT as a good transducer. The potential drift $(\Delta \mathrm{E} / \Delta \mathrm{t})$ in cases of absence and presence of MWCNT was recorded as 270.0 and $6.3 \mu \mathrm{V} / \mathrm{s}$, respectively. The previous results reflect the high performance of the proposed sensor in the presence of MWCNT, which increases the conductance and decreases the resistance and the potential drift over the time of the measurements. 


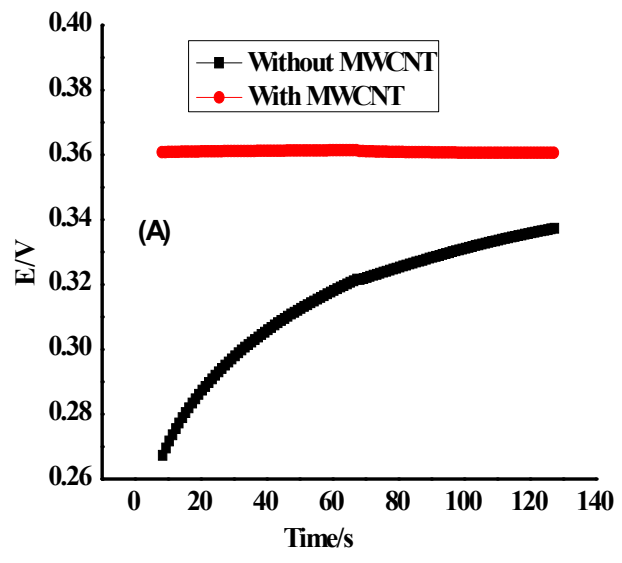

(A)

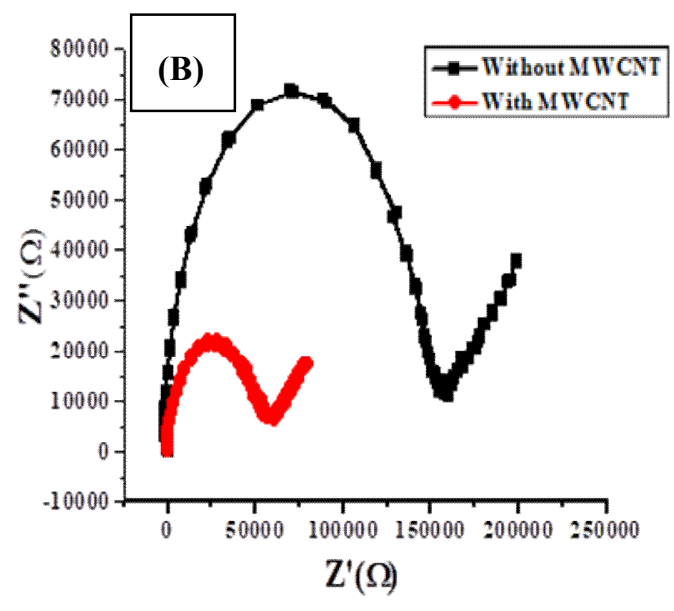

(B)

Figure 9. (A) Chronopotentiometry and (B) impedance plot for FLX/MIP-ISEs, with and without MWCNT as a solid contact material. Abbreviations: ion-selective electrodes (ISEs).

\subsection{Electrochemical Impedance Spectrometry (EIS)}

The electrochemical impedance (EIS) measurements were tested by using the same device that was used in $\mathrm{CP}$ measurements. The range of frequencies were applied between $100 \mathrm{kHz}$ to $0.1 \mathrm{~Hz}$ using a sinusoidal excitation signal with an excitation amplitude of $0.01 \mathrm{~V}$ of open-circuit potential [41]. Figure 9B show the Nyquist plots on the equivalent circuit models. The two plots of the proposed sensor in the presence and absence of MWCNT reflect resistance of the membrane value equal to 0.06 and $0.16 \mathrm{M} \Omega$, respectively. The double layer capacitances $\left(\mathrm{C}_{\mathrm{dl}}\right)$ were estimated from the low-frequency branch (semicircle), which were valued as 86.9 and $42.4 \mu \mathrm{F}$ in the case of the presence and absence of MWCNT, respectively. These values exhibited due to the nano-structured features of MWCNTs, which generate a large double-layer capacitance and increase the potential stability. The geometric capacitances $\left(C_{g}\right)$ were estimated at high frequencies part that valued as 1.5 and $0.6 \mathrm{nF}$ for presence and absence of MWCNT, respectively. The whole results exhibited from CP and EIS reflect the enhancement of the performance of the applied sensor in the presence of MWCNT, which helps to increase the capacitance and decrease the potential drift duration of the measurements.

\subsection{Analytical Applications}

The exhibited data from FLX determination in different dosage forms by using the proposed sensor are shown in Table 3. Recoveries' results were ranged between $98.6 \%-101.1 \%$. The results were compared with the reference method of HPLC from British Pharmacopeia (B.P.) [42]. The $t$-student and $F$-tests were calculated for two methods and showed no significant difference between the two methods, which confirms that the proposed method is an applicable and efficient method of FLX determination in their different matrices. 
Table 3. FLX determination in pharmaceutical preparations using the proposed membrane sensor and reference method.

\begin{tabular}{|c|c|c|c|c|c|c|c|}
\hline \multirow[b]{2}{*}{ Pharmaceutical Product and Source } & \multirow[b]{2}{*}{ Nominal Content Taken, $\mathrm{mg} \mathrm{tablet}^{-1}$} & \multicolumn{4}{|c|}{ Found, mg tablet ${ }^{-1}$} & \multirow[b]{2}{*}{$\mathrm{t}$-Student Test } & \multirow[t]{2}{*}{$F$-Tes } \\
\hline & & Proposed Method & $\begin{array}{l}\text { Mean a }(\%) \\
\pm \text { SD }\end{array}$ & $\begin{array}{l}\text { Reference Method } \\
{[42]}\end{array}$ & $\begin{array}{l}\text { Mean a (\%) } \\
\pm \text { SD }\end{array}$ & & \\
\hline Prozac (Lilly, France) & 20 & 20.2 & $101.0 \pm 0.3$ & 20.1 & $100.8 \pm 0.6$ & 0.4 & 4.4 \\
\hline Philozac (Amoun, Egypt) & 20 & 19.8 & $99.2 \pm 0.6$ & 19.9 & $99.1 \pm 1.7$ & 0.2 & 8.7 \\
\hline $\begin{array}{l}\text { Flutin } \\
\text { (Fipico Eoypt) }\end{array}$ & 20 & 20.3 & $101.1 \pm 0.6$ & 19.8 & $99.4 \pm 0.9$ & 2.3 & 2.6 \\
\hline Depreban (Amirya, Egypt) & 20 & 19.7 & $98.6 \pm 0.4$ & 19.4 & $97.2 \pm 0.8$ & 1.7 & 2.9 \\
\hline
\end{tabular}

${ }^{\mathrm{a}}$ Mean of three replicate measurements \pm standard deviation (SD). ${ }^{\mathrm{b}} t$-Student and F-test at $95 \%$ confidence level values are $4.30,19.00$ respectively. 


\section{Conclusions}

A facile and validated potentiometric method for fluoxetine (FLX) monitoring based on solid-contact ISEs was presented. MIP for FLX was prepared, dispersed in plasticized PVC membrane and drop-casted on the orifice of the screen-printed electrode. A multi-walled carbon nanotube (MWCNT) was used as nanomaterial for the ion-to-electron transduction process. The presented sensor revealed a stable response with a Nernstian slope of $58.9 \pm 0.2 \mathrm{mV} /$ decade and a detection limit of $2.1 \times 10^{-6} \mathrm{~mol} / \mathrm{L}$ in $10 \mathrm{mmol} / \mathrm{L}$ acetate buffer of $\mathrm{pH} 4.5$. The effect of plasticizers on the potentiometric response and selectivity behavior was studied. The presented miniaturized ISEs revealed enhanced repeatability, reproducibility and stability. Validation of the assay method with the proposed ISE sensors, by measuring the lower detection limit, range, accuracy, precision, repeatability and between-day-variability, reveals good performance characteristics confirming applicability for continuous determination of FLX in pharmaceutical formulations.

Author Contributions: The listed authors contributed to this work as described in the following: H.M.H., E.M.A.B. and A.H.K., gave the concepts of the work, interoperated the results, the experimental part and prepared the manuscript; H.M.H., S.S.M.H., A.H.K. and A.E.-G.E.A. cooperated in the preparation of the manuscript and A.H.K. and A.E.-G.E.A. performed the revision before submission. A.E.-G.E.A. revealed the financial support for the work. All authors read and approved the final manuscript.

Funding: Through Researchers Supporting Project (Project No. RSP-2019/66).

Acknowledgments: Authors are grateful to King Saud University for funding the work through Researchers Supporting Project (Project No. RSP-2019/66).

Conflicts of Interest: The authors declare no conflict of interest.

\section{References}

1. WHO. Depression: A Global Crisis. World Mental Health Day. Available online: http://www.emro.who.int/ media/news/mental-health-day2012.html (accessed on 16 June 2012).

2. Desouky, D.; Allam, H. Occupational stress, anxiety and depression among Egyptian teachers. J. Epidemiol. Glob. Health 2017, 7, 191-198. [CrossRef] [PubMed]

3. Wong, D.T.; Perry, K.W.; Bymaster, F.P. The discovery of fluoxetine hydrochloride (Prozac). Nat. Rev. Drug Discov. 2005, 4, 764-774. [CrossRef] [PubMed]

4. Pigott, T.A.; Seay, S.M. A review of the efficacy of selective serotonin reuptake inhibitors in obsessive-compulsive disorder. J. Clin. Psychiatry 1999, 60, 101-106. [CrossRef] [PubMed]

5. Darwish, I.A.; Amer, S.M.; Abdine, H.H.; Al-Rayes, L.I. New spectrophotometric and fluorimetric methods for determination of fluoxetine in pharmaceutical formulations. Int. J. Environ. Anal. Chem. 2009, 2009, 1-9. [CrossRef]

6. Bigdelifam, D.; Mirzaei, M.; Hashemi, M.; Amoli-Diva, M.; Rahmani, O.; Zohrabi, P.; Taherimaslak, Z.; Turkjokar, M. Sensitive spectrophotometric determination of fluoxetine from urine samples using charge transfer complex formation after solid phase extraction by magnetic multiwalled carbon nanotubes. Anal. Methods 2014, 6, 8633-8639. [CrossRef]

7. Nezhadali, A.; Motlagh, M.O.; Sadeghzadeh, S. Spectrophotometric determination of fluoxetine by molecularly imprinted polypyrrole and optimization by experimental design, artificial neural network and genetic algorithm. Spectrochim. Acta Part A Acta A Mol. Biomol. Spectrosc. 2018, 190, 181-187. [CrossRef]

8. Parmar, V.K.; Patel, J.N.; Jani, G.K.; Prajapati, L.M.; Gagoria, J. FIRST derivative spectrophotometric determination of fluoxetine hydrochloride and olanzapine in tablets. Int. J. Pharm. Sci. Rev. Res. 2011, 2, 2996.

9. Murtada, K.; de Andrés, F.; Ríos, A.; Zougagh, M. Determination of antidepressants in human urine extracted by magnetic multiwalled carbon nanotube poly (styrene-co-divinylbenzene) composites and separation by capillary electrophoresis. Electrophoresis 2018, 39, 1808-1815. [CrossRef]

10. Catai, A.P.F.; Carrilho, E.; Lanças, F.M.; Queiroz, M.E.C. Fast separation of selective serotonin reuptake inhibitors antidepressants in plasma sample by nonaqueous capillary electrophoresis. J. Chromatogr. A 2009, 1216, 5779-5782. [CrossRef] 
11. Himmelsbach, M.; Buchberger, W.; Klampfl, C.W. Determination of antidepressants in surface and waste water samples by capillary electrophoresis with electrospray ionization mass spectrometric detection after preconcentration using off-line solid-phase extraction. Electrophoresis 2006, 27, 1220-1226. [CrossRef]

12. Ghorbani, M.; Esmaelnia, M.; Aghamohammadhasan, M.; Akhlaghi, H.; Seyedin, O.; Azari, Z.A. Preconcentration and Determination Of Fluoxetine and Norfluoxetine in Biological and Water Samples with $\beta$-cyclodextrin Multi-walled Carbon Nanotubes as a Suitable Hollow Fiber Solid phase Microextraction Sorbent and High Performance Liquid Chromatography. J. Anal. Chem. 2019, 74, 540-549. [CrossRef]

13. Wróblewski, K.; Petruczynik, A.; Waksmundzka-Hajnos, M. Separation and determination of selected psychotropic drugs in human serum by SPE/HPLC/DAD on C18 and Polar-RP columns. J. Liq. Chromatogr. Relat. Technol. 2017, 40, 75-82. [CrossRef]

14. Song, L.; Zheng, Z.; Liang, C.; Chen, X.; Zhang, R.; Hong, Z.; Chai, Y. Rapid solid-phase extraction coupled with GC-MS method for the determination of venlafaxine in rat plasma: Application to the drug-drug pharmacokinetic interaction study of venlafaxine combined with fluoxetine. J. Sep. Sci. 2017, 40, 3462-3468. [CrossRef] [PubMed]

15. Erarpat, S.; Cağlak, A.; Bodur, S.; Chormey, S.D.; Engin, Ö.G.; Bakırdere, S. Simultaneous Determination of Fluoxetine, Estrone, Pesticides, and Endocrine Disruptors in Wastewater by Gas Chromatography-Mass Spectrometry (GC-MS) Following Switchable Solvent-Liquid Phase Microextraction (SS-LPME). Anal. Lett. 2019, 52, 869-878. [CrossRef]

16. González Martín, M.; González Pérez, C. Batch and flow injection fluorimetric determination of fluoxetine. Anal. Lett. 1997, 30, 2493-2502. [CrossRef]

17. Lencastre, R.P.; Delerue-Matos, C.; Garrido, J.; Borges, F.; Garrido, E.M. Voltammetric quantification of fluoxetine: Application to quality control and quality assurance processes. J. Food Drug Anal. 2006, 14, 242-246.

18. Da Silva, A.R.; Lima, J.; Teles, M.O.; Brett, A.O. Electrochemical studies and square wave adsorptive stripping voltammetry of the antidepressant fluoxetine. Talanta 1999, 49, 611-617. [CrossRef]

19. Nouws, H.P.; Delerue-Matos, C.; Barros, A.A.; Rodrigues, J.A.; Santos-Silva, A.; Borges, F. Square-wave adsorptive-stripping voltammetric detection in the quality control of fluoxetine. Anal. Lett. 2007, 40, 1131-1146. [CrossRef]

20. Alizadeh, T.; Azizi, S. Graphene/graphite paste electrode incorporated with molecularly imprinted polymer nanoparticles as a novel sensor for differential pulse voltammetry determination of fluoxetine. Biosens. Bioelectron. 2016, 81, 198-206. [CrossRef]

21. Mostafa, G.; Hefnawy, M.; El-Majed, A. PVC membrane sensor for potentiometric determination of fluoxetine in some pharmaceutical formulations. Instrum. Sci. Technol. 2008, 36, 279-290. [CrossRef]

22. Hussien, E.; Abdel-Gawad, F.; Issa, Y. Ion-selective electrodes for determination of fluoxetine in capsules and in biological fluids. Biochem. Eng. J. 2011, 53, 210-215. [CrossRef]

23. Arvand, M.; Rad, N.A. Determination of fluoxetine in pharmaceutical preparations and biological samples using potentiometric sensors based on polymeric membranes. J. Anal. Chem. 2013, 68, 183-188. [CrossRef]

24. Abdalla, N.S.; Amr, A.E.G.E.; El-Tantawy, A.S.M.; Al-Omar, M.A.; Kamel, A.H.; Khalifa, N.M. Tailor-made specific recognition of cyromazine pesticide integrated in a potentiometric strip cell for environmental and food analysis. Polymers 2019, 11, 1526. [CrossRef] [PubMed]

25. Ezzat, S.A.; Ahmed, M.; Amr, E.; El-Galil, A.; AAl-Omar, M.H.; Kamel, A.; Khalifa, N.M. Single-Piece All-Solid-State Potential Ion-Selective Electrodes Integrated with Molecularly Imprinted Polymers (MIPs) for Neutral 2, 4-Dichlorophenol Assessment. Materials 2019, 12, 2924. [CrossRef] [PubMed]

26. Galal Eldin, A.; Amr, E.; El-Galil, A.; HKamel, A.S.M.; Hassan, S. Screen-printed Microsensors Using Polyoctyl-thiophene (POT) Conducting Polymer As Solid Transducer for Ultratrace Determination of Azides. Molecules 2019, 24, 1392. [CrossRef]

27. El-Naby, E.H.; Kamel, A.H. Potential transducers based man-tailored biomimetic sensors for selective recognition of dextromethorphan as an antitussive drug. Mater. Sci. Eng. C 2015, 54, 217-224. [CrossRef]

28. El-Kosasy, A.; Kamel, A.H.; Hussin, L.; Ayad, M.F.; Fares, N. Mimicking new receptors based on molecular imprinting and their application to potentiometric assessment of 2, 4-dichlorophenol as a food Taint. Food Chem. 2018, 250, 188-196. [CrossRef] 
29. Abdalla, N.S.; Youssef, M.A.; Algarni, H.; Awwad, N.S.; Kamel, A.H. All solid-state poly (vinyl chloride) membrane potentiometric sensor integrated with nano-beads imprinted polymers for sensitive and rapid detection of bispyribac herbicide as organic pollutant. Molecules 2019, 24, 712. [CrossRef]

30. Elbehery, N.H.A.; Amr, A.E.G.E.; Kamel, A.H.; Elsayed, E.A.; Hassan, S.S.M. Novel potentiometric 2,6-Dichlorophenolindophenolate (DCPIP) membrane-based sensors: Assessment of their input in the determination of total phenolics and ascorbic acid in beverages. Sensors 2019, 19, 2058. [CrossRef]

31. Hassan SS, M.; Amr AE, G.E.; El-Naby, H.A.; El-Naggar, M.; Kamel, A.H.; Khalifa, N.M. Novel aminoacridine sensors based on molecularly imprinted hybrid polymeric membranes for static and hydrodynamic drug quality control monitoring. Materials 2019, 12, 3327. [CrossRef]

32. Saber, A.L.; Elmosallamy, M.A.; Killa, H.M.; Ghoneim, M.M. Selective potentiometric method for determination of flucloxacillin antibiotic. J. Taibah Univ. Med. Sci. 2013, 7, 195-201. [CrossRef]

33. Khaled, E.; Hassan, H.; Mohamed, G.G.; Seleim, A. Carbon paste and PVC electrodes for the flow injection potentiometric determination of dextromethorphan. Talanta 2010, 81, 510-515. [CrossRef] [PubMed]

34. Kudo, Y. Potentiometric Determination of Ion-Pair Formation Constants of Crown Ether-Complex Ions with Some Pairing Anions in Water Using Commercial Ion-Selective Electrodes. In Electrochemistry; Intech: Rijeka, Croatia, 2013. [CrossRef]

35. Othman, A.; Rizka, N.; El-Shahawi, M. Potentiometric determination of dopamine in pharmaceutical preparations by crown ether-PVC membrane sensors. Anal. Sci. 2004, 20, 651-655. [CrossRef] [PubMed]

36. Attiyat, A.S.; Christian, G.D.; Bartsch, R.A. Potentiometric selectivity study of crown ethers containing four ring oxygen atoms and benzoxymethyl or carboxylic acid side chains as ionophores for lithium and potassium. Electroanalysis 1989, 1, 63-67. [CrossRef]

37. Arada Pérez, M.A.; Cortés Nodarse, I.; Yazdani-Pedram Zobeiri, M.; Pérez Saavedra, J.J. Effect of Plasticizer Type on the Potentiometric Selectivity Coefficient (KAPot) of Electrodes for Nitrate Ion Determination Constructed by Using PVC as Polymeric Membrane. Revista Cubana de Química 2003, 15, 36-43.

38. Mihali, C.; Vaum, N. Use of plasticizers for electrochemical sensors. In Recent Advances of Plasticizer; InTech: Rijeka, Croatia, 2012.

39. Procedures, A. Methods Validation: Chemistry, Manufacturing, and Controls. Fed. Regist. 2000, 65, 52776-52777.

40. Buck, R.P.; Lindner, E. Recommendations for nomenclature of ionselective electrodes (IUPAC Recommendations 1994). Pure Appl. Chem. 1994, 66, 2527-2536. [CrossRef]

41. Electrochemistry, P.; Elements, C.; Equivalent, C.; Models, C. Basics of electrochemical impedance spectroscopy. Appl. Note AC 2010, 286, R491-R497.

42. U.P. USP30-NF25; US Pharmacopoeial Convention, Inc.: Rockville, MD, USA, 2007. 